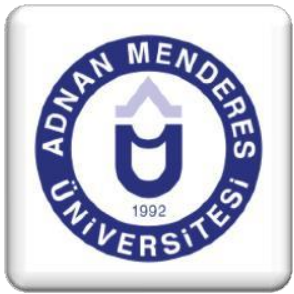

\title{
Enerji ve Büyümenin Çevre Kirliliğine Etkisi: AB Ülkeleri İçin Panel Veri Analizi
}

M. Metin DAM ${ }^{1}$

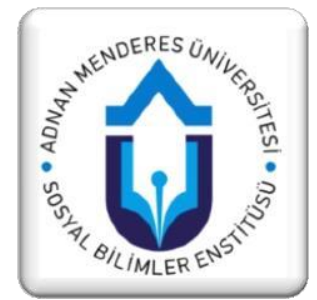

\section{Özet}

$\mathrm{Bu}$ çalışmada, $\mathrm{AB}$ ülkeleri için ekonomik büyümenin ve enerji tüketiminin çevre kirliliği üzerindeki etkisi 2000-2015 dönemi yıllık veriler kullanılarak panel veri analiziyle araştırılmıştır. Değişken olarak kişi başı GSYH, kişi başı enerji tüketimi ve kişi başı karbondioksit emisyonun alındığı model tahmin edilmiştir. Panel veri analizi yöntemiyle elde edilen sonuçlara göre enerji tüketiminin çevre üzerindeki etkisi pozitif ve istatistiksel olarak anlamlıdır.

Anahtar Kelimeler: Küresel Isınma, Çevre Kirliliği, Ekonomik Büyüme, Enerji Tüketimi, Panel Veri Analizi.

Jel Sinıflandırması: Q54, F43, C33

\section{The Impact of Economic Growth on Environmental Pollution: Panel Data Analysis for EU Countries}

\begin{abstract}
In this study, the impact of economic growth end energy consumption for EU countries on environmental pollution was tested using the annual data for the period 2000-2015 using panel data analysis. As a variable, per capita GDP, per capita energy consumption and per capita carbon dioxide emissions were used and a model was estimated. According to the empirical analysis results obtained by panel data method, the effect of energy consumption on the environment is positive and statistically significant.
\end{abstract}

Key Words: Global Warming, Environmental Pollution, Economic Growth, Energy Consumption, Panel Data Analysis.

JEL Classification: Q54, F43, C33

1 Dr. Öğr. Üyesi, Adnan Menderes Üniversitesi, Nazilli İktisadi ve İdari Bilimler Fakültesi, Uluslararas1 Ticaret ve Finansman Bölümü, metindam@ hotmail.com 


\section{Giriş}

Bilimin gelişmesi, yerkürede meydana gelen değişimleri en ince ayrıntısına kadar öğrenmeyi mümkün kılmıştır. Yerkürenin tehlikeli bir değişim olgusu olan iklim değişikliği konusu bilim adamlarından sivil toplum örgütlerine kadar her seviyede ilgi çekmiştir. Öyle ki iklim değişikliği ile küresel ısınma çok sık karıştırılan terimler olmuştur.

Her bilimsel çalışmada neden sonuç ilişkisi kurulduğu gibi bir sonuç olarak ele alınan iklim değişikliğinin nedeni olarak küresel 1sınma yazılabilir. Kısaca yaşadığımız yerkürede ortalama sıcaklığın uzun dönemde artması manasına gelen küresel isınma dünyanın başlıca sorunları arasında yer almaktadır. Evrensel bir sorun olan küresel 1sınmayı önleme amaçlı dünya genelinde çeşitli girişimler olsa da henüz yeterli seviyeye ulaşmamıştır.

Küresel ısınma sera etkisinden dolayı oluşmaktadır. Sera etkisine sebep olan gazların başında karbondioksit gazı gelmekle birlikte azot oksit, metan, su buharı ve kloroflorokarbonlar bunlardandır. Ancak karbondioksit $\left(\mathrm{CO}_{2}\right)$ gazının bu gazlar arasındaki oranının \%82 olması (Özçağ, 2011: 8) sebebiyle yapılan akademik çalışmalar ve alınan tedbirler karbondioksit gazı üzerine yoğunlaşmıştır.

Dünyanın ilk yıllarından itibaren doğal denge gereği karbondioksit gazı bitkiler tarafindan absorbe edilmiş ve karbon döngüsü devam etmiştir. Su ve buhar gücü ile mekanik üretimlerin başladığı Birinci Sanayi Devrimi’nin ardından oluşan İkinci Sanayi Devrimi elektrik kullanımı arttırması ile birlikte fosil yakıtların tüketimini de arttırmıştır. Sırasıyla fabrikalarda üretimin artması enerji ihtiyacını doğurmuş, bu sebeple fosil yakıtlar kullanılmaya başlanmış, fosil yakıtların kullanılmasıyla karbondioksit oranı artmıştır. Karbon döngüsünün absorbe edemediği karbondioksit dünyaya gelen ışınların yansıyıp geri dönmesine engel olduğu için sıcaklığın artmasına sebep olmuştur. Gelişen teknoloji ve refah düzeyi yükselen ülkeler daha temiz enerji kaynaklarına arayışına girişmiş ve var olan enerji kaynaklarının kullanımı ile ilgili birtakım kısıtlamalara gitmiştir. Ekonomisi gelişmiş öncü $\mathrm{AB}$ ülkeleri yasal yaptırımlarla birlikte karbon emisyonunun azaltılması konusunda ne kadar etkili oldukları bundan sonra yapılacak çalışmalar ve kısıtlamalar için önemli bir sorudur. $\mathrm{Bu}$ sebeple ekonomisi dünya ortalamasının üzerinde olan $\mathrm{AB}$ ülkelerinin tarih boyunca ekonomileri ile ülkelerinde üretilen karbondioksit emisyon oranları arasındaki ilişkinin varlığı araştırılmıştır.

$\mathrm{Bu}$ çalışmada, enerji tüketimi ve ekonomik büyümenin çevre üzerindeki etkisi ekonometrik yöntemler kullanılarak incelenmiştir. Çalışmanın birinci bölümünde iklim değişikliği, küresel ısınma ve çevre kirliliği kavramları, ikinci bölümünde teorik çerçeve, üçüncü bölümde $\mathrm{AB}$ ülkelerinde çevre, ekonomik büyüme ve enerji tüketimi, dördüncü bölümde tarih siralamasına göre literatür özeti, beşinci bölümde analiz ve son bölümde ise sonuç ve değerlendirme yer almaktadır.

\section{Teorik Çerçeve}

Çevre kirliliği, arasında bulunduğu gazlar içerisinde oranı en yüksek olan karbondioksit gazı yani karbon emisyonu ile ilişkilendirilmiştir. Nitekim literatürde karbondioksit ile hava kirliliğini açıklayan birçok çalışma mevcuttur. Bu çalışmalar üç kategoride incelenebilir. Birincisi enerji tüketimi ve ekonomik büyüme arasındaki ilişki, ikincisi çevre kirliliği ve ekonomik büyüme ilişkisi ve üçüncüsü ekonomik büyüme, enerji tüketimi ve kirletici emisyonların ilişkisidir (Farhani \& Rejeb 2012: 74). Son yirmi yıldır bu alanda yapılan çalışmaların artış gösterdiği görülmektedir (Dritsaki \& Dritsaki 2014: 128). 
Dünya nüfusundaki artış ve ekonomik gelişmeler çevresel problemi de beraberinde getirmiştir. Dünya Nobel fizik ödülünü alan Simon Kuznets 1955 yılındaki çalışmasında; ülkelerde kişi başına düşen milli gelirin artmasıyla harcamalar artacak ve çevre kirliği artmaya başlayacaktır. Bu gelir belirli bir eşik değerine ulaşınca hane halkları ve ülkelerin çevreye olan duyarlılıkları artacağı ve alınacak tedbirlerle çevre kirliliğinin azalmaya başlayacağı vurgulanmıştır (Dam, 2014: 75).

\section{AB Ülkelerinde Durum}

Dünya nüfusunun artması ve özellikler kentlerde yoğunlaşması sonucu son dönemlerde çevre kirliliği sorunları artmaya başlamıştır. Yapılan ampirik çalışmalarda çevre kirliliği göstergesi olarak çoğunlukla karbon dioksit emisyonu kullanılmıştır. Günümüzde karbon emisyonları daha çok fosil yakıtlardan elde edilmektedir. Gelişmiş AB ülkeleri büyüme ve rekabet avantajını korumak istemesi enerjiye olan ihtiyacını arttırmaktadır (Apergis \& Payne, 2009).

Kyoto Protokolü'ne (KP) göre, Ek I Tarafları, sera gazı emisyonlarını (2008- 2012 dönemi) 1990 yılı düzeyinin en az \% 5 altına düşürmekle mükelleftir.

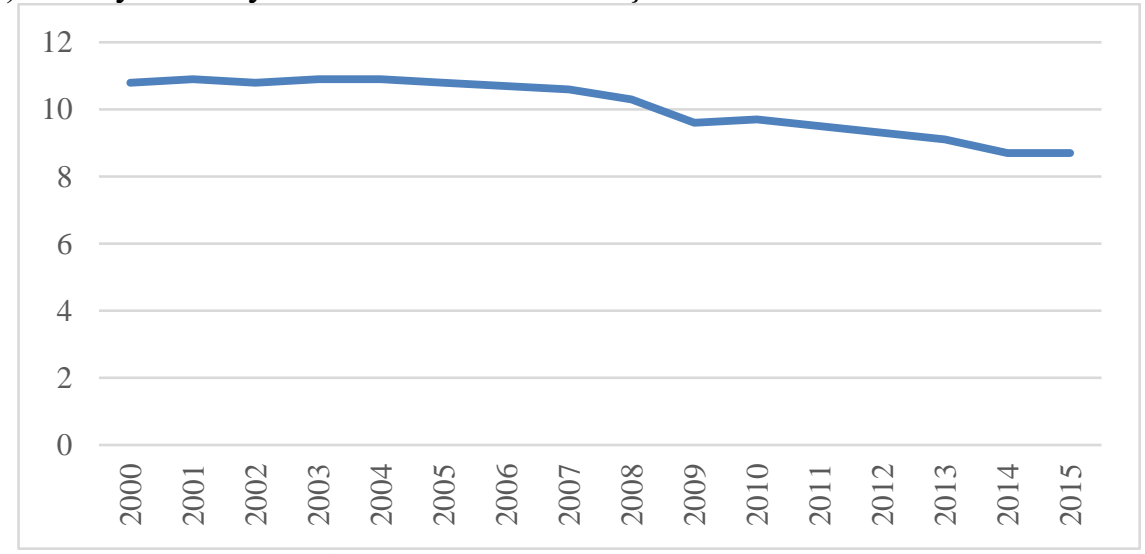

Şekil 1: AB Ülkelerinde Kişi Başı CO2 Emisyonu (metrik ton) Kaynak: Eurostat

Şekil 1'de AB ülkelerinde 2000-2015 dönemi kişi başı karbon emisyonları verilmiştir. Eurostat 2015 yılı verilerine göre AB ortalama kişi başı salımı 8.2 Ton Karbondioksit Eşdeğeridir (t CO2e). Yine aynı yıla ait en düşük salım 5.7 t CO2e Hırvatistan ve İsveç iken en yüksek salım 20.5 t CO2e ile Lüksemburg'tur. Bu salımın 12342 milyon ton OECD ülkeleri gerçekleştirmiştir. OECD üyelerinin yaklaşık üçte ikisine sahip gelişmiş AB ülkeleri 1980 yılına kadar gelirleriyle doğru orantılı olarak çevreyi kirletmiş fakat uygulamış oldukları Kyoto Protokolü Esneklik Mekanizmaları sayesinde bu tarihten sonra karbon salımlarını azaltmıştır. Bu şekil aynı zamanda Kuznets Teorisinin gerçekliğini göstermektedir. 


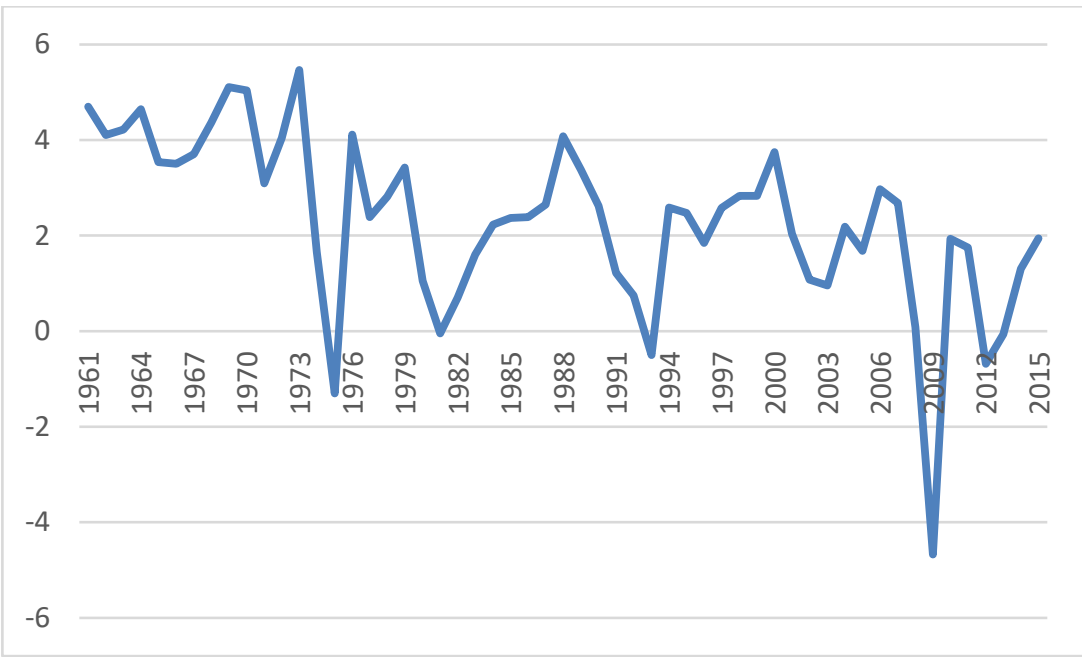

Şekil 2: AB Ülkelerinde Ekonomik Büyüme Oranı (\%)

Kaynak: WDI

Şekil 2'de AB ülkelerindeki 1961-2015 dönemi ekonomik büyüme oranı verilmiştir. Bu verilere göre, 1974 yılında meydana gelen petrol krizi başta Avrupa Birliği ülkeleri olmak üzere birçok ülkeyi etkilemiştir. Bu dönemde hızlı büyüyen $\mathrm{AB}$ ekonomisi küçülmüştür. 2007 yılında ABD'deki emlak piyasasında başlayan kriz birçok büyük şirketi iflasa sürüklemiş ve bunun zincirleme etkisiyle kriz $\mathrm{AB}$ ülkelerine ve diğer ülkelere yayılmıştır. Dünyanın en büyük ikinci krizi olarak bilinen 2008 krizi AB ülkelerinin ekonomik olarak küçültmüş ve bu krizin etkisi bazı $\mathrm{AB}$ ülkelerinde halen sürmektedir.

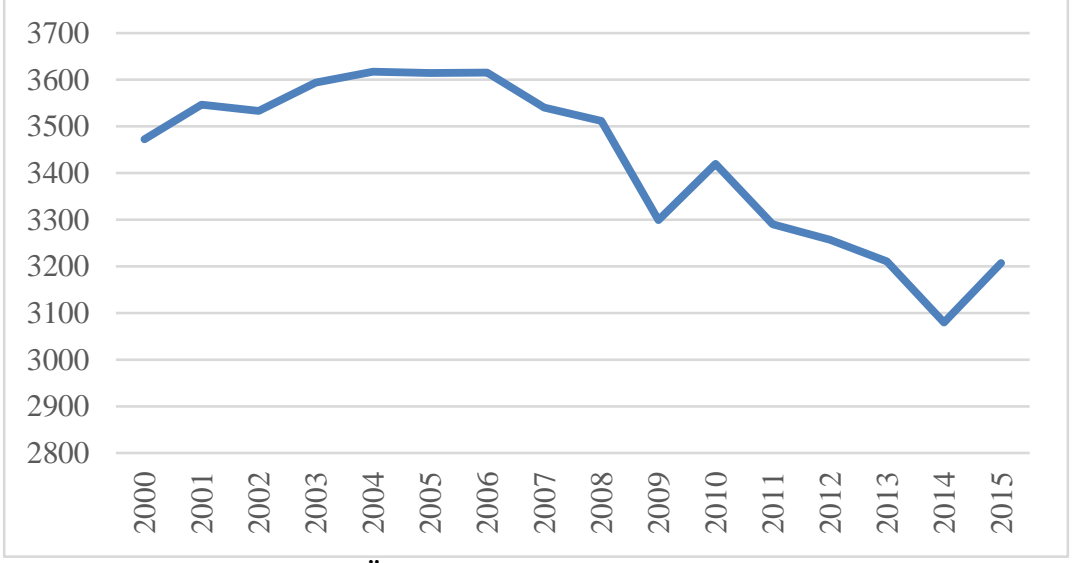

Şekil 3: AB Ülkelerinde Kişi Baş1 Enerji Tüketimi

Kaynak: WDI

Şekil 3'te AB ülkelerinde 2000-2015 dönemi kişi başı enerji tüketimi verilmiştir. Dünya Bankası 2015 yılı verilerine göre $A B$ ülkelerinde kişi başı en çok enerji tüketen ülke Lüksemburg iken en az enerji tüketen ülke ise Romanya'dır. 2000-2015 y1lları arasında enerji tüketimini en çok arttıran ülke 1.4 kat ile Letonya birinci, Bulgaristan ve Litvanya 1.2 katla ikinci sırada yer almaktadır. Bu süre içinde enerji tüketimini en az arttıran ülke ise 0.7 katla İngiltere'dir.

\section{Literatür Özeti}

1997 yılında Japonya'nın Kyoto şehrinde imzalanan Kyoto Protokolü ile çevre ve ekonomik büyüme ilişkisi arasında yapılan çalışmalarda bir artış olduğu görülmektedir. Ülke bazında zaman serisi olarak yapılan çalışmalar olduğu gibi yatay kesit ve zaman boyutunu barındıran panel veri analiz yöntemleriyle yapılmış çalışmalar da mevcuttur. 
Özellikle ekonomik değerlerin yükselmesiyle karbon emisyonlarının salınımının bir süre sonra düşüşe geçmesini ifade eden ters U şeklindeki Çevresel Kuznets Eğrisi üzerine incelemelerin yapıldığı göze çarpmaktadır. Bu alanda yapılan başlıca çalışmaları şu şekilde sıralayabiliriz;

Selden \& Song, çevre ve büyüme arasındaki ilişki 1994 yılında panel veri yöntemiyle incelemiş ve bu değişkenler arasında Ters-U şeklinde bir ilişki olduğunu gözlemlemiştir.

Selden ve Song, ayrıca karbondioksit dışında karbonmonoksit, sülfürdioksit, nitrojenoksit gibi değişkenlerin de gelirle Ters-U şeklinde bir ilişkisi olduğu analiz edilmiştir.

Holtz-Eakin ve Selden, 1995 yılında yaptıkları çalışmada, sera gazlarının küresel ısınmanın habercisi olup olamayacağı incelemiştir. Analizde ekonomik büyümenin hızının CO2 emisyonlarının oranını yıllık veya kümülatif bir şekilde fazlaca etkilemediği gözlenmiştir.

Heil \& Selden, 1999 yılındaki çalışmasında panel veri yöntemlerini kullanarak karbondioksit emisyonları ve gayri safi yurtiçi hasıla serilerinin durağanlığg incelemiş, analizde 1973'ten sonra yapısal kırılmaya izin verilmiştir ancak birim kökün varlığı reddedilmiştir.

Hamilton \& Turton, OECD ülkeleri için 2002 yılında yaptıkları çalışmada büyüme, enerji ve sera gazı ilişkisini 1982-1997 dönemi verileriyle incelemiştir. Analiz sonucunda ABD ve $A B$ 'nin enerji yoğunlukları düşerken Japonya'nın enerji yoğunluğunda artış gözlenmiştir.

Lise, ekonomik büyüme ile karbon emisyonları arasındaki ilişkiyi Türkiye için 2006 y1lında 1980-2003 denemi verilerini kullanarak araştırmıştır. Araştırılan dönemde ekonomik büyümesi hızlı olan Türkiye'nin karbon emisyonlarının da artma eğiliminde olduğu vurgulanmıştır. Artan bu karbon emisyonlarının azaltılmasının enerji yoğunluğunun düşürülerek olabileceği ifade edilmiştir.

Soytaş vd. 2007 yılında ABD için enerji tüketimi, gelir ve karbon emisyonları arasındaki ilişki incelenmiş ve yapılan analiz sonucunda enerji tüketimi ile karbon emisyonları arasında bir nedensellik ilişkisi tespit edilmiştir ancak ekonomik büyüme ile karbon emisyonları arasında herhangi bir nedensellik ilişkisi bulunamamıştır.

Akbostanc1 vd. zaman serisi yöntemiyle 2009 yılında 1968-2003 dönemi verileriyle Türkiye için yaptığı çalışmada, kişi başı gelir ile karbon emisyonları arasındaki ilişkiyi incelemiştir. Ampirik analiz sonucunda, uzun dönemde kişi başı gelir ile karbon emisyonları arasında artan bir monoton ilişki saptanmıştır.

Jaunky, 36 gelişmiş ülke için 1980-2005 dönemi veriler kullanarak 2011 y1lında GSYIH ile karbon emisyonları arasındaki ilişkiyi panel veri analizi yöntemiyle incelemiştir. Analiz sonucunda, GSYH'daki 100br'lik artış kısa dönemde karbon emisyonlarını 68br arttırırken, uzun dönemde $22 \mathrm{br}$ arttırdığ 1 tespit edilmiştir.

Arı \& Zeren, 2011 yılında, nüfus, karbon emisyonları ve kişi başı gelir arasındaki ilişkiyi Türkiye ve Akdeniz ülkeleri için araştırmıştır. Panel veri analizi yönteminin kullanıldığ 1 çalışmanın sonucunda nüfus artışının ve enerji tüketiminin çevre kirliliği üzerinde pozitif bir etkisinin olduğu belirtilmiştir.

Ahmed \& Long, Pakistan'da 2012 yılında 1971-2008 dönemi yıllık verilerini kullanarak karbon emisyonu, büyüme, ticaret ve nüfus değişkenlerini modele dahil etmiştir. Sınır testi eş-bütünleşme yönteminin kullanıldığı çalışma sonucunda enerji tüketimi ve ekonomik büyümeyle çevresel kirlenme arasında ilişki olduğu tespit edilmiştir.

Dam, 2014 yılındaki tez çalışmasında, sera gazı emisyonları ile makroekonomik değişkenler arasındaki ilişki 1971-2011 dönemi yıllık veriler kullanılarak OECD ülkeleri için panel veri analizi yöntemiyle incelenmiştir. Sera gazı olarak $\mathrm{CO}_{2}$ emisyonu, 
makroekonomik değişken olarak ekonomik büyüme, enerji tüketimi ve ticari açıklık kullanılmıştır. Panel veri analizinin kullanıldığı çalışmada 24 OECD ülkesi için Kuznets Hipotezi sınanmış ancak EKC hipotezini doğrulanmadığı sonucuna varılmıştır.

Çağlar \& Mert, 2017 yılında Türkiye için yaptığı çalışmada, 1960-2013 dönemi seriler için EKC hipotezini sınamış ve yenilebilir enerji ile sera gazı emisyonları arasındaki ilişkiyi incelemiştir. Ampirik analiz sonucunda, yenilenebilir enerji ile sera gazı salımı arasında ters bir ilişki olduğu vurgulanmıştır. Bunun yanında EKC hipotezi test edilmiş ve Türkiye'de bu hipotezin geçerli olduğu sonucuna ulaşılmıştır.

Mirza \& Kanval (2017) Pakistan için yaptığı çalışmada enerji tüketimi, karbon emisyonu ve ekonomik büyüme serilerini kullanmıştır. Analiz sonucunda kısa ve uzun dönemde bu üç değişken arasında çift yönlü güçlü bir Granger nedensellik ilişkisi tespit etmiştir.

\section{Analiz}

\subsection{Veri Seti}

Bu çalışmada Avrupa Birliği’nin 28 ülkesine ${ }^{2}$ ait, 2000-2015 dönemi, y1llık verileri kullanılmıştır. Karbondioksit emisyonu, ekonomik büyüme ve enerji tüketimi değişkenlerine ait veriler Çizelge 1'de verilmiştir.

Çizelge 1: Veri Seti

\begin{tabular}{|c|c|c|c|c|}
\hline Değişken & Sembol & Temsil Eden Değişken & Kullanımı & Kaynak \\
\hline Çevre Kirliliği & CO & $\begin{array}{c}\text { Kişi Başı Karbon } \\
\text { Emisyonu (metric tons } \\
\text { per capita) }\end{array}$ & Logaritmik & Eurostat \\
\hline Ekonomik Büyüme & $G D P$ & $\begin{array}{c}\text { Kişi Başı Gelir (constant } \\
\text { 2010 US\$) }\end{array}$ & Logaritmik & WDI \\
\hline Enerji Tüketimi & EC & $\begin{array}{c}\text { Enerji Tüketimi (kg of oil } \\
\text { equivalent per capita) }\end{array}$ & Logaritmik & WDI \\
\hline
\end{tabular}

\subsection{Model}

$\mathrm{Bu}$ çalışmada enerji tüketimi ve ekonomik büyümenin çevre kirliliği üzerindeki etkisi incelenmiştir. Bu çalışmadaki beklenti literatürdeki birçok çalışma gibi enerji tüketimi ve ekonomik büyümenin çevre kirliliğini arttıracağı yönündedir. Bu ilişkinin şekli Model 1'de ekonometrik olarak tahmin edilmiştir (Narayan \& Narayan, 2010: 662; Ar1 \& Zeren, 2011: 41).

Model : $C O_{i t}=\alpha_{i t}+\alpha_{1 i t} G D P_{i t}+\alpha_{2 i t} E C_{i t}+\varepsilon_{i t}$

\subsection{Yöntem}

$\mathrm{AB}$ ülkelerine ait verilerle analiz yapabilmek için ülke ve zaman boyutlarını göz önüne alan panel veri analizi yöntemi kullanılmıştır (Constantini \& Martini, 2006; Bella, Massidda \& Etzo, 2011). Panel veri analizi:

$$
Y_{i t}=\propto_{i}+\beta X_{i t}+u_{i t}
$$

\footnotetext{
${ }^{2}$ Avusturya, Belçika, Bulgaristan, Hırvatistan, Kıbrıs, Çek Cumhuriyeti, Danimarka, Estonya, Finlandiya, Fransa, Almanya, Yunanistan, Macaristan, İrlanda, İtalya, Letonya, Litvanya, Lüksemburg, Malta, Hollanda, Polonya, Portekiz, Romanya, Slovakya, Slovenya, İspanya, İsveç, Birleşik Krallı.
} 
Model 2'deki $\left(Y_{i t}\right)$ terimi bağımlı değişken olan kişi başı karbondioksit emisyonunu, $\left(\propto_{i}\right)$ terimi gözlenemeyen birim etkiyi, $\left(X_{i t}\right)$ terimi bağımsız değişken olan kişi başı GSYH'deki yüzde değişimi ve $\left(u_{i t}\right)$ terimi hata terimini ifade etmektedir. Terimlerin alt simgeleri olan i ülkeleri, t de zamanı belirtmektedir. (Stolyarova, 2009: 11; Arı ve Zeren 2011: 42)

Panel veri analizi yöntemlerinde model tahmini yapılırken sahte regresyon problemleri ile karşılaşmamak için serilerin durağan olup olmadığı kontrol edilmiştir. Bu sebeple serilerin durağanlığ 219). Yapılan birim kök testlerinden sonra gözlenemeyen etkilerin varlığını kontrol etmede sabit veya rassal etkiler modeli kullanılmıştır. Sonuç olarak tahmin edilen analizde değişen varyans ve otokorelasyon sorunları doğrulama testleri yapılmıştır (Arı ve Zeren, 2011: 42).

\subsection{Panel Birim Kök Testi}

Bu çalışmada, serilerin durağanlığı 2002 yılında Levin, Lin \& Chu tarafindan bulunan LLC testi kullanılmıştır. Testte kullanılan $\mathrm{H}_{0}$ hipotezi ortak birim kök olduğu yönündedir. $\mathrm{H}_{1}$ hipotezi ise serinin durağın olduğu yönündedir. Test olasılık değerinin 0.05 'ten küçük olması serilerin durağan olduğunu; 0.05 'ten büyük olması ise serilerde birim kök olduğunu göstermektedir (Çınar, Yılmazer \& Fazlılar 2012: 219; Akbostancı, Aşık \& Tunç 2009: 866).

Çalışmada uygulanan LLC panel birim kök testi sonuçları Çizelge 2'de verilmiştir.

Çizelge 2: LLC Panel Birim Kök Testi Sonuçları

\begin{tabular}{|c|c|c|c|c|}
\hline Değişken & $\begin{array}{c}\text { Düzey } \\
\text { Değeri }\end{array}$ & $\begin{array}{c}\text { Olasılık } \\
\text { Değeri }\end{array}$ & 1. Fark & $\begin{array}{c}\text { Olasılık } \\
\text { Değeri }\end{array}$ \\
\hline$C O$ & 4.02 & 1.00 & $-4.78^{* *}$ & 0.00 \\
\hline$G D P$ & $-4.24 * *$ & 0.00 & $-7.75^{* *}$ & 0.00 \\
\hline Not: ** ve * sirasılyla \%1 ve \%10 anlamlılık düzeyinde serilerin durağan olduğunu göstermektedir.
\end{tabular}

Çizelge 2'deki sonuçlara göre GDP serisi düzeyde durağan iken, CO ve EC serileri birinci farkları alındıktan sonra durağan hale gelmiştir. Seriler durağan hale geldikten sonra panel EKK yöntemiyle tahmin edilecektir.

Literatürde yapılan çalışmalarda ele alınan örneklem geniş bir coğrafyaya dağıldığında rassal etkiler modeli kullanılmaktadır. Belirli bir bölge veya benzer gruplar seçildiğinde ise sabit etkiler modeli tercih edilmektedir. Çalışmaya alınan AB ülkeleri bu bağlamda sabit etkiler modeli ile tahmin edilmesi beklenmektedir. Analize dahil edilen örneklem grubun sabit veya rassal etkiler modelinin kullanılması gerektiğini ölçmek amacıyla LM testi uygulanmaktadır. LM testini doğrulamak amacıyla da Hausman testi sınanmıştır.

\subsection{LM Testi (Breush-Pagan Lagrange Multiplier)}

Bireysel ve zaman etkilerinin sabit veya rassal olarak seçilmesini öngören LM testi, analize alınan örneklemin belirli bir gurubu temsil etmesi bireysel etkilerin sabit olacağını ve ele alınan dönemde ekonomik dalgalanmaların olması zaman etkilerinin rassal 
olacağını belirtmektedir. Bu bağlamada etkilerin sabit veya rassal olduğuna LM testi karar vermektedir (Baltagi, 2001:15).

LM testi üç test şeklinde yapılmaktadır. LM1 testi bireysel etkileri, LM2 testi zaman etkilerini ve LM testi hem bireysel hem de zaman etkilerini göstermektedir.

LM1 testi; $\mathrm{H}_{0}: \sigma_{\mu}^{2}=0$ Bireysel etkiler yoktur. Karş1 hipotez bireysel etkiler vardır şeklindedir. LM1 test sonucu olasılık değeri, 0.05'ten büyük olması, $\mathrm{H}_{0}$ '1n kabul edilmesi ve bireysel etkilerin sabit olduğuna karar verilmektedir.

LM2 testi; $\mathrm{H}_{0}: \sigma_{\lambda}^{2}=0$ Zaman etkileri yoktur. Karş1 hipotez zaman etkileri vardır şeklindedir. LM2 test sonucu olasılık değeri, 0.05 'ten büyük olmas1, $\mathrm{H}_{0}$ '1n kabul edilmesi ve zaman etkilerinin sabit olduğuna karar verilmektedir.

$\mathrm{LM}=\mathrm{LM} 1+\mathrm{LM} 2$ testi şeklinde yazılabilir.

$\mathrm{H}_{0}: \sigma_{\mu}^{2}=\sigma_{\lambda}^{2}=0$, Bireysel etkiler ve zaman etkileri yoktur.

Karşı hipotez;

$\mathrm{H}_{1}: \sigma_{\mu}^{2} \neq 0$ veya $\sigma_{\lambda}^{2} \neq 0$ ya da her ikisi de $\neq 0$, Etkilerden en az biri ya da ikisi de rassaldır.

LM testi olasıllk değerlerinin 0.05 'ten büyük olması, $\mathrm{H}_{0}$ '1n kabul edilmesi, yani bireysel ve zaman etkilerinin sabit olduğuna karar verilmektedir ve bu durumda çift yönlü sabit etkiler modeli kullanılmaktadır. LM test sonuçları Çizelge 3'te verilmiştir.

Çizelge 3: LM Testi

\begin{tabular}{|c|c|c|}
\hline Test & $\begin{array}{c}\text { Olasılık } \\
\text { Değeri }\end{array}$ & Karar \\
\hline $\mathrm{LM}_{1}$ & 0.13 & Bireysel Etkiler sabittir \\
\hline $\mathrm{LM}_{2}$ & 0.00 & Zaman Etkileri Rassaldır \\
\hline $\mathrm{LM}$ & 0.07 & $\begin{array}{c}\text { Bireysel Etkiler ve Zaman } \\
\text { Etkileri sabittir }\end{array}$ \\
\hline
\end{tabular}

Çizelge 3'te, LM test sonuçlarına göre LM1; bireysel etkilerin sabit olduğu, LM2; zaman etkilerinin rassal olduğu; LM1 ve LM2 test sonuçlarını kapsayan LM testi bireysel ve zaman etkilerin sabit olduğunu göstermektedir. Modelin geneli için kullanılan LM test sonucu çift yönlü sabit etkiler modelinin kullanılacağı sonucuna ulaşılmıştır.

\subsection{Hausman Testi}

LM testini doğrulamak amacıyla yapılan Hausman testi, rassal etki modelinde gözlenemeyen etkiyle açıklayıcı değişken arasında herhangi bir ilişkinin olmadığ varsayılır. Yapılan bu varsayım Hausman testiyle sinanır (Ar1 \& Zeren 2011: 42).

Hausman testi sonucunda Chi2 $=19.38$ ve Chi2 olasılık değeri 0.00 olarak bulunmuştur. Olasılık değerinin 0.05 'ten küçük olması sonucu $\mathrm{H}_{0}$ hipotezi kabul edilmiş̧ir. $\mathrm{Bu}$ sonuç aynı zamanda modelde herhangi bir içsellik probleminin olmadığı anlamına gelmektedir. LM testi sonucunu destekleyen bu sonuca göre çift yönlü sabit etkiler model tahmincisi kullanılmalıdır. 


\section{7. Çift Yönlü Sabit Etkiler Modeli}

Çift yönlü sabit etkiler modeli tahmincisi, sabit terimin birimler boyunca değişen doğrusal bir regresyon modelidir. Sabit etkiler regresyon modelinin her birimi için bir tane olmak üzere $\mathrm{n}$ tane farklı sabit terim vardır. Bu sabit terimler gösterge değişkenleri ile temsil edilir. Gösterge değişkenleri birimden birime değişen, fakat zamanla sabit olan dışlanan bütün değişkenlerin etkilerini içine aldığı varsayılmaktadır.

Çift yönlü sabit etkiler modeliyle tahmin edilen veriler Çizelge 4'te sunulmuştur.

Çizelge 4: Tahmin Sonuçları

\begin{tabular}{|l|c|c|c|}
\hline \multirow{2}{*}{ Değişken } & \multicolumn{3}{|c|}{ Model } \\
\cline { 2 - 4 } & Katsayı & t-İstatistiği & Olasılık Değeri \\
\hline$L C O(-1)$ & 0.482 & 13.754 & 0.000 \\
\hline$L G D P$ & -0.084 & -4.748 & 0.000 \\
\hline LEC & 0.724 & 16.016 & 0.000 \\
\hline Sabit Terim & -0.241 & -0.909 & 0.363 \\
\hline & \multicolumn{3}{|c|}{ Tanısal Testler } \\
\hline $\mathrm{R}^{2}=0.98$ Düzeltilmiş $\quad \mathrm{R}^{2}=0.98 \mathrm{~F}_{\text {ist }}=1138.07(0.000)$ \\
\hline
\end{tabular}

Çift yönlü sabit etkiler modeli, ağırlıklandırılmış istatistik değerleri içermektedir (Baltagi, 2001: 21). Çizelge 4'de ağırlıklandırılmış verilere göre model tahmini güvenilir olduğu ortaya çıkmaktadır. Model tahminine göre elde edilen sonuçların istatistiki olarak anlamlı oldukları ve beklentileri karşıladıkları görülmektedir. Analiz sonuca göre; enerji tüketimi 100 birim arttığında karbondioksit emisyonu 72 birim artmaktadır. Yani pozitif yönlü bir ilişki vardır. Ancak kişi başı gelirdeki 100 birimlik artış karbon emisyonlarını 8 birim azaltmaktadır. Modelde tanısal testlerin anlamlı olduğunu analizin doğruluğunu desteklemektedir.

\section{Sonuç ve Değerlendirme}

İklim değişikliği günümüzde hissedilmekle birlikte gelecek yıllarda daha belirgin bir şekilde ortaya çıkacağı öngörülmektedir. İklim değişikliğine sebep olan küresel 1sınma ise sera gazı etkisinden dolayı oluşmaktadır. Sera gazının büyük çoğunluğunu oluşturan karbondioksit gazı ile enerji tüketimi arasındaki ilişkinin pozitif çıkması beklentileri karşılamaktadır. AB ülkelerinin esneklik mekanizmalarıyla sera gazı emisyonlarını 1990 yılının altına indirmeye çalışmaları ve bu gelişmiş ülkelerdeki ekonomik büyümenin yavaş olması kişi başı gelir arttıkça az da olsa çevre kirliliğinin azaldığını göstermektedir.

Yapılan analizde, çevre kirliliğini arttıran en önemli değişkenin enerji tüketimi olduğu görülmektedir. Gelişmiş $\mathrm{AB}$ ülkelerinde kişi başı enerji tüketiminin yüksek olması ve elde edilen enerjinin yaklaşık olarak \%80'in fosil yakıtlardan elde edilmesi kirliliği arttırmaktadır. AB ülkelerinde teknolojinin gelişmiş olması yenilebilir enerji kaynaklarına talebi attırsa da fosil yakıtların kullanımı devam etmektedir. 
Çalışma sonucunda elde edilen verilere göre enerji tüketimi artışı ile karbondioksit gazı artışı kaçınılmaz olduğundan birtakım tedbirlerin alınması ve var olan tedbirlerin sürdürülebilir olması gerekmektedir. Bu amaçla yapılan uluslararası anlaşmalar, karbon vergisi kanuni değişikliklere istisnasız bir şekilde uyulması gerekmektedir. Karbon emisyonuna sebep olan fosil yakıtlar yerine yenilebilir enerji kaynakları kullanılmalı, alternatif teknolojiler üretilmelidir. Bireylerin bilinçlenmesi sonucu doğal dengeye verilecek zarar en alt düzeye indirilerek ve var olan küresel ısınma sorunu da çözüme kavuşturulmalıdır. 


\section{KAYNAKÇA}

AHMED, K. \& LONG, W. (2012). Environmental Kuznets Curve and Pakistan: An Empirical Analysis. Procedia Economics and Finance, 1, 4-13

AKBOSTANCI, E., AŞIK, S. \& TUNÇ, İ. (2009). The Relationship between Income and Environment in Turkey: Is There an Environmental Kuznets Curve?. Energy Policy, 37, 861-867.

APERGIS, N. \& PAYNE, J. (2009). CO2 Emissions, Energy Usage and Output in Central America. Energy Policy, 37, 3282-3286.

ARI, A. \& ZEREN, F. (2011). CO2 Emisyonu ve Ekonomik Büyüme: Panel Veri Analizi. Yönetim ve Ekonomi, 18 (2), 37-47.

BALTAGI, B. H. (2001). Econometric Analysis of Panel Data. 2. Ed., New York: John Wiley \& Sons.

BELlA, G., MASSIDDA, C. \& ETZO, I. (2010). A Panel Estimation of The Relationship between Income, Electric Power Consumption and $\mathrm{CO} 2$ Emissions, MPRA Paper, 26077. https://mpra.ub.unimuenchen.de/26077/1/MPRA_paper_26077.pdf

CONSTANTINI, V. \& MARTINI, C. (2006). A Modified Environmental Kuznets Curve for Sustainable Development Assessment Using Panel Data, Climate Change Modelling and Policy, https://www.econstor.eu/bitstream/10419/73900/1/NDL2006-148.pdf

ÇAĞLAR, A.E. \& MERT, M. (2017). Türkiye'de Çevresel Kuznets Hipotezi ve Yenilenebilir Enerji Tüketiminin Karbon Salımı Üzerine Etkisi: Yapısal Kırılmalı Eşbütünleşme Yaklaşımı. Yönetim ve Ekonomi, 24 (1), 21-38.

ÇINAR, S., YILMAZER, M. \& FAZLILAR, T. (2012). Kirlilik Yaratan Sektörlerin Ticareti ve Çevre: Gelişmiş ve Gelişmekte Olan Ülkeler Karş1laştırması. Doğuş Üniversitesi Dergisi, 13 (2), 212-256.

DAM, M.M. (2014). Sera Gazı Emisyonlarının Makroekonomik Değişkenlerle İlişkisi: OECD Ülkeleri İçin Panel Veri Analizi, Yayınlanmamış Doktora Tezi, Adnan Menderes Üniversitesi, Sosyal Bilimler Enstitüsü: Aydın.

DIJKGRAAF, E. \& VOLLEBERGH, H. (2001). A Note on Testing for Environmental Kuznets Curves with Panel Data. Climate Change Modelling and Policy. http://econwpa.repec.org/eps/othr/papers/0409/0409001.pdf

DRITSAKI, C. \& DRITSAKI, M. (2014). Causal Relationship between Energy Consumption, Economic Growth and CO2 Emissions: A Dynamic Panel Data Approach. International Journal of Energy Economics and Policy, 2(4), 125-136

FARHANI, S. \& REJEB, J. (2012). Energy Consumption, Economic Growth and CO2 Emissions: Evidence from Panel Data for MENA Region. International Journal of Energy Economics and Policy, 2 (2), 71-81.

HAMILTON, C. \& TURTON, H. (2002). Determinant of Emissions Growth in OECD Countries. Energy Policy, 30, 63-71.

HEIL, M.T. \& SELDEN, T.M. (1999). Panel Stationarity with Structural Breaks: Carbon Emissions and GDP. Applied Economics Letters, 6 (4), 223-225. 
HOLTZ-EAKIN, D. \& SELDEN, T.M. (1994). Stoking the Fires? $\mathrm{CO}_{2}$ Emissions and Economic Growth. Journal of Public Economics, 57, 85-101.

JAUNKY, V.C. (2011). The $\mathrm{CO}_{2}$ Emissions-Income Nexus: Evidence from Rich Countries. Energy Policy, 39, 1228-1240.

MIRZA, F.M. \& KANVAL, A. (2017). Energy consumption, carbon emissions and economic growth in Pakistan: Dynamic causality analysis. Renewable and Sustainable Energy Reviews, 72, 1233-1240.

NARAYAN, P.K. \& NARAYAN, S., (2010). Carbon Dioxide and Economic Growth: Panel Data Evidence from Developing Countries. Energy Policy, 38, 661-666.

LEVIN, A., LIN, C. \& CHU C.J. (2002). Unit Root Tests in Panel Data: Asymptotic and Finite-sample Properties. Journal of Econometrics, 108, 1-24.

LISE, W. (2006). Decomposition of $\mathrm{CO}_{2}$ Emissions over 1980-2003 in Turkey. Energy Policy, 34, 1841-1852.

SELDEN, T.M. \& SONG, D. (1994). Environmental Quality and Development: Is There a Kuznets Curve for Air Pollution Emisions?. Journal of Environmental Economics and Management, 2 (27), 147-162.

ÖZÇAĞ, M. (2011). Insan Kaynaklı İklim Değişikliği ve Ekonomik Büyüme Türkiye Üzerine Bir Analiz. Yayınlanmamış Doktora Tezi, Adnan Menderes Üniversitesi, Sosyal Bilimler Enstitüsü: Aydın.

SONG, T., ZHENG, T. \& TONG, L. (2008). An Empirical Test of The Environmental Kuznets Curve in China: A Panel Cointegration Approach. China Economic Review, 3 (19), 381-392.

STOLYAROVA, E. (2009). Carbon Dioxide Emissions, Economic Growth and Energy Mix: Empirical Evidence from 93 Countries. Climate Economics Chair, ParisDauphine University.

ŞAHINÖZ, A. \& FOTOUREHCHI, Z. (2013). Çevresel Kuznets Eğrisi: İndirgenmiş ve Ayrıştırılmış Modellerle Ampirik Bir Analiz. H.Ü. İktisadi ve İdari Bilimler Fakültesi Dergisi, 31 (1), 199-224. 